\title{
Health related quality of life in juvenile SLE patients- use of the PedsQL 3.0 rheumatology module
}

\author{
Helena Sousa*, Margarida Guedes \\ From 18th Pediatric Rheumatology European Society (PReS) Congress \\ Bruges, Belgium. 14-18 September 2011
}

\section{Background}

Juvenile SLE (jSLE) is a multisystemic chronic condition associated with significant morbidity consequential to the disease and treatment with negative impact in the quality of life of the patients and their families.

\section{Aim}

to assess the health related quality of life (HRQOL) in the jSLE patients followed in the Pediatric Department of Santo António Hospital - Porto Hospital Center (Portugal).

\section{Methods}

The PedsQL 3.0 Rheumatology Module to adolescents (ages 13-18) (Portuguese translation), including teen self report and parent proxy report, and its instructions was sent by mail to the six jSLE patients of our Pediatric Department. Adolescents and their parents should fill the forms separately and return by mail. The queries were unidentified so the answers were anonymous. Data were analysed in EXCELL.

\section{Results}

All the six queries were receipt with no missing data. Clinical data of the 6 jSLE patients: 5 \% $/ 10^{\text {; }}$; mean age $15,5 \pm 2,07$ years, disease onset at $12( \pm 3,52)$ years old with mean disease duration $3,42( \pm 2,4)$ years. Lupic nephritis in 2 and secondary antiphospholipid syndrome in 3. Mean SLEDAI score 3,3 (maximum 8). All patients were on chloroquine and prednisone. Other immnossupressive drugs included: rituximab; azathioprine and cyclophosphamide courses; mycophenolate mofetil; methotrexate and intravenous immunoglobulins. Antiaggregant therapy in three and ACE-I in 2.

Santo António-Porto Hospital Center, PORTO, Portugal
Table 1

\begin{tabular}{llllll}
\hline \multicolumn{7}{c}{$\begin{array}{l}\text { PedsQL 3.0 Rheumatology module to adolescents } \\
\text { (ages 13-18) }\end{array}$} \\
\hline \multicolumn{5}{c}{ Teen report } & \multicolumn{3}{l}{$\begin{array}{l}\text { Parent report for } \\
\text { teens }\end{array}$} \\
\hline Scale & $\mathrm{N}^{\circ}$ items & Mean (\%) & SD & Mean (\%) & SD \\
\hline Pain and hurt & 4 & 66,67 & 16,14 & 64,58 & 20,02 \\
\hline Daily activities & 5 & 91,07 & 11,23 & 86,67 & 17,51 \\
\hline Treatment & 7 & 83,33 & 10,26 & 76,77 & 5,88 \\
\hline Worry & 3 & $\mathbf{3 0 , 5 6}$ & 38,61 & $\mathbf{1 3 , 8 9}$ & 11,38 \\
\hline Communication & 3 & 73,61 & 23,81 & 63,89 & 34,82 \\
\hline
\end{tabular}

Table 1 presents the results obtained in the teen self report and parent proxy report on the five domains of the PedsQL 3.0 Rheumatology module.

\section{Conclusion}

The results were similar in the teen and parent report. In both reports four of the five domains obtained positive $(>50 \%)$ results. The low results attained in the worry scale alert to the need of improving the psychological support to these patients and their families.

The authors consider important in the approach of jSLE patients the regular evaluation of the HRQOL; besides allowing a more active participation of the adolescent in the disease, gives to the clinician a more holistic information and alarm for underestimated needs.

Published: 14 September 2011

doi:10.1186/1546-0096-9-S1-P243

Cite this article as: Sousa and Guedes: Health related quality of life in juvenile SLE patients- use of the PedsQL 3.0 rheumatology module. Pediatric Rheumatology 2011 9(Suppl 1):P243.

\section{Biomed Central}

(C) 2011 Sousa and Guedes; licensee BioMed Central Ltd. This is an open access article distributed under the terms of the Creative Commons Attribution License (http://creativecommons.org/licenses/by/2.0), which permits unrestricted use, distribution, and reproduction in any medium, provided the original work is properly cited. 